\title{
Experimental investigation on the effect of different slot shapes and configurations on scour dimension downstream of flip buckets
}

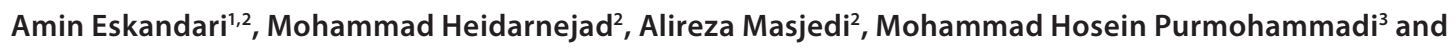 \\ Amirabbas Kamanbedast ${ }^{2}$ \\ 'Department of Water Science Engineering, Khouzestan Science and Research Branch, Islamic Azad University, Ahvaz, Iran \\ ${ }^{2}$ Department of Water Science Engineering, Ahvaz Branch, Islamic Azad University, Ahvaz, Iran \\ ${ }^{3}$ Department of Water Science Engineering, Shoushtar Branch, Islamic Azad University, Shoushtar, Iran
}

Flip buckets at the end of a spillway can dissipate the flood discharge energy. Compared to other energy dissipators, this is a cost-effective structure. The formation of a scour hole downstream of a flip bucket is a topic of interest among hydraulic engineers. The current study investigated scouring downstream of a flip bucket under two major scenarios: (i) free conditions, and (ii) slotted conditions with rectangular and triangular slots configured differently under four different discharge rates. In total, 20 experiments were conducted in this study. Results showed that the use of a deflector slot greatly affected the scour extent and depth, resulting in a greater scour reduction (53\%) in the labyrinth rectangular slotted bucket compared to the solid bucket. The results were compared to empirical equations, and a high correlation was observed between them. In comparison, the Taraimovich equation produced more accurate results in control experiments, and the Damle-A and Damle-B equations produced more accurate results in experiments corresponding to labyrinth rectangular and triangular slotted buckets.

\section{INTRODUCTION}

The flows discharging down spillways have high velocity and energy, which are super-critical. If not dissipated, this energy can result in the formation of scour downstream of the structure and cause irreparable damage. A solution to this problem is the application of a stilling basin; however, since this is a very costly structure, other types of energy dissipators can be used. For example, flip buckets are among the common methods for energy dissipation by creating free impinging jet flows into the downstream submergence basin. Although it is a common method in terms of implementation, jet flow and its impingement on the downstream bed results in scour-caused topographical changes that endanger the safety of the hydraulic structure. In this type of energy dissipator, the jet flow is deflected upward and impinges on the stream bed a far distance away from the dam body, resulting in erosion at that location. Erosion is one of the major issues in hydraulic structures that may occur in many different situations. Jet flow released from hydraulic structures, specifically dams, causes erosion downstream resulting in sediment transfer along the river. This phenomenon is associated with many negative impacts, specifically dam body instability, which may result in its collapse following scour enlargement. Scour prediction and estimation have always interested researchers in the field of hydraulic science. Figure 1 presents the schematic of scour downstream of a flip bucket.

There are two types of flip buckets: solid buckets (Fig. 2) and slotted buckets (Fig. 3). In a solid bucket, the whole flow is conducted upwards before hitting the downstream area, whereas in a slotted bucket a portion of the flow is dissipated by passing through the slots. As a result, the flow is distributed over a greater area, thereby increasing the efficiency of energy dissipation (Vischer and Hager, 1995; Taraimovich, 1978).

The current study investigated the formation of scour downstream of a solid and slotted flip bucket with rectangular and triangular slots forming straight and labyrinth configurations. Extensive studies have been conducted on scouring. For example, Mason and Arumugam (1985) examined the scour downstream of a flip bucket caused by free falling jets. They concluded that the flip bucket deflects the high-velocity flow (jet) upward away from the structure, thereby affecting the flow passing through the bucket end and energy dissipation by changing the bucket trajectory angle. This mechanism leads to better performance of this structure than other energy dissipators. Vischer and Hager (1995) conducted a laboratory study into the effect of a series of prismatic slots on the flip bucket and concluded that a series of prismatic slots with smaller base width and a greater number of slots along a trajectory channel have a greater impact on the scour depth. They also emphasized the importance of slot configuration on the flip bucket as a topic for further study. Amanian (1993) investigated the formation of scour downstream of spillways with flip buckets and concluded that the scour depth increases by increasing the angle of the impinging jet. In addition, he found that the scour hole length increases as the angle of jet trajectory decreases. Hoffmans and Verheij (1997) proposed a semianalytical equation for estimation of the maximum scour depth using Newton's second law. Mahboobi (1996) examined the scour formed by vertical free-falling jets and developed an equation to estimate the maximum scour depth caused by free-falling vertical jets through applying statistical regression on laboratory observations. He also investigated the effect of tailwater depth on the scour and

\section{CORRESPONDENCE}

Mohammad Heidarnejad

EMAIL

mo_he3197@yahoo.com

\section{DATES}

Received: 1 October 2018

Accepted: 27 June 2020

\section{KEYWORDS}

flip buckets energy dissipation scour depth rectangular and triangular slots labyrinth configuration

\section{COPYRIGHT}

(c) The Author(s)

Published under a Creative

Commons Attribution 4.0

International Licence

(CC BY 4.0) 


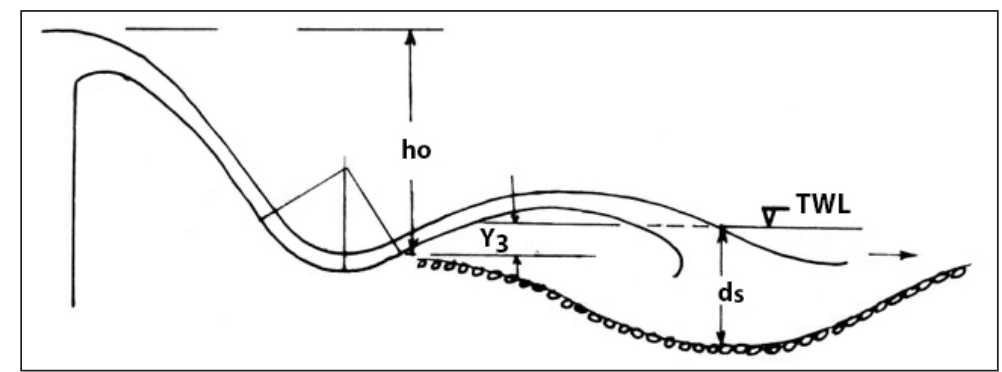

Figure 1. Schematic presentation of scour at downstream of flip bucket: $d_{s}=$ depth of scour below tailwater level, in $m$; TWL = tailwater level, $\mathrm{h} 0=$ spillway crest elevation minus initial scour hole, $\mathrm{Y}_{3}=$ tailwater level minus initial scour hole

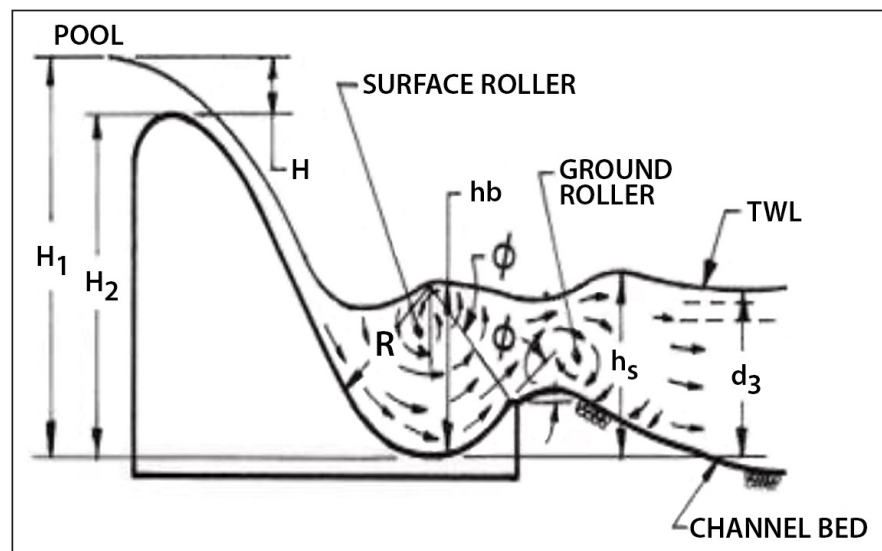

Figure 2. Solid bucket (Bhavan and Shahzafar, 2010): $d_{3}=$ height of tailwater above bucket invert, $h b=$ height of roller above bucket invert; $h_{s}=$ height of surge above bucket invert; $\mathrm{H}$ = depth of overflow over spillway; $\mathrm{H}_{1}=$ reservoir pool elevation minus bucket invert elevation; $\mathrm{H}_{2}=$ spillway crest elevation minus bucket invert elevation; $T W L=$ tailwater level; $R=$ radius of bucket; $\phi=$ the flip bucket trajectory angle; $v_{a}=$ actual velocity

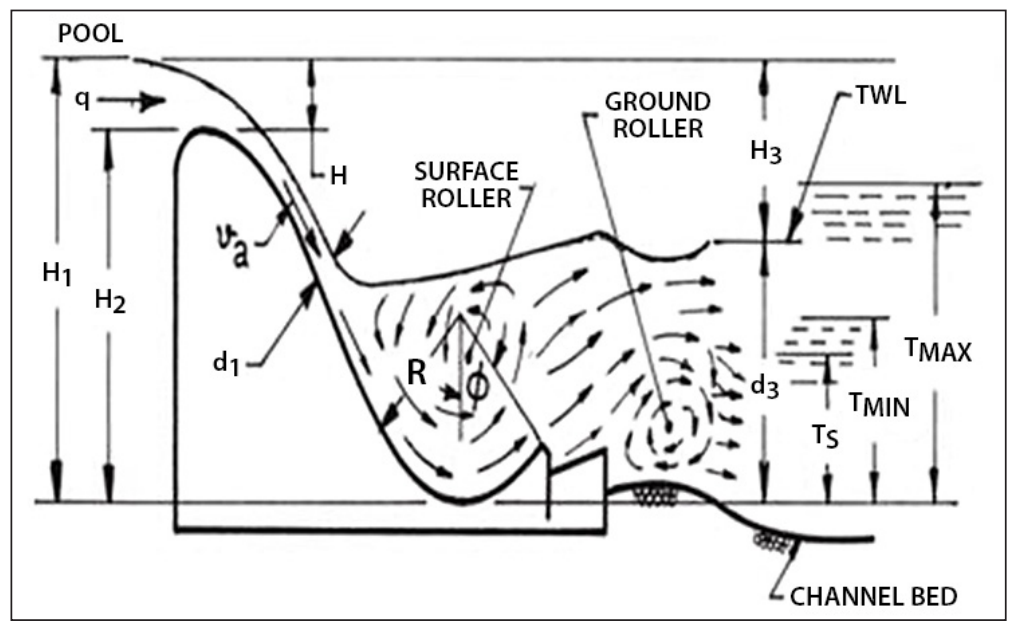

Figure 3. Slotted bucket (Bhavan and Shahzafar, 2010): $\mathrm{H}_{3}=$ reservoir pool elevation minus tailwater; $\mathrm{H}=$ depth of overflow over spillway; $\mathrm{R}=$ radius of bucket; $\mathrm{T}_{\text {MAX }}=$ maximum tailwater depth, above bucket; $\mathrm{T}_{\text {MIN }}=$ minimum tailwater depth, above bucket; $\mathrm{TWL}=$ tailwater level; $\phi=$ the flip bucket trajectory angle; $v_{a}=$ actual velocity; $d_{1}=$ depth of flow entering bucket; $d_{3}=$ height of tailwater above bucket invert; $q=$ discharge intensity per meter of bucket width; $T_{s}=$ tailwater sweep out depth

observed that the maximum scour depth increased by decreasing the tailwater depth. Moreover, an increase in tailwater depth affected the scour shape and the bank formed by eroded materials, resulting in a gradual shape shift from trapezoidal to triangular, as well as an increase in the bank height. Mazurek and Rajaratnum (2003) investigated the scour formed by vertical impingement of a circular jet on non-adhesive materials with low tailwater levels, and concluded that the scour depth is a function of the particle Froude number. Hager and Minor (2004) investigated scour changes in the presence and absence of jets and concluded that the jet flow increases the scour depth and should be considered in designs. Momeni Vesalian et al. (2008) investigated scours formed by rectangular jets downstream of flip buckets with non-uniform materials, and showed that their proposed linear and exponential regression models were able to successfully predict the maximum scour depth. Pirestani et al. (2009) conducted studies on the effects of tailwater depth on downstream scouring and concluded that the scour hole dimensions depend on upstream head, discharge, and tailwater depth. Mehrkia et al. (2012) investigated the equations governing scour formation downstream of flip buckets using field and laboratory data. They concluded that in all provided equations, the extent of scouring is directly related to the discharge per unit width and projectile head. Akbari et al. (2014) investigated scouring downstream of flip buckets and introduced Martins-B model as the best scour predictor. Pirestani and Riazi (2015) performed an experimental investigation into the effect of slots and gate opening of flip buckets on bed profile with nonuniform materials. They concluded that the scour hole enlarges by increasing the discharge rate; however, the tailwater depth showed a decreasing trend. 


\begin{tabular}{|c|c|}
\hline Researcher & Relation \\
\hline Chee and Padiyar & $D=1.663 q^{0.6} H^{0.2} / d_{m}{ }^{0.1}$ \\
\hline Martins, B & $D=1.5 q^{0.6} H^{0.1}$ \\
\hline Damle, A & $D=0652 q^{0.5} H^{0.5}$ \\
\hline Damle, B & $D=0.543 q^{0.5} H^{0.5}$ \\
\hline Schoklitsch & $D=0.521 q^{0.57} H^{0.2} / d_{90}^{0.32}$ \\
\hline Veronese, $\mathrm{A}$ & $D=0.202 q^{0.54} H^{0.255} / d_{m}^{0.42}$ \\
\hline Veronese, B & $D=1.9 q^{0.54} H^{0.255}$ \\
\hline Azmathullah & $\frac{D}{h_{t}}=6.916\left(\frac{q}{{\sqrt{g h_{t}}}^{3}}\right)^{0.694}\left(\frac{H}{h_{t}}\right)^{0.0815}\left(\frac{R}{h_{t}}\right)^{-0.233}\left(\frac{d_{50}}{h_{t}}\right)^{0.196} \varnothing^{0.196}$ \\
\hline Mason & $D=k q^{x} H^{y} h^{w} / g^{v} d^{z}, k=\left(6.42-3.1 / H^{0.1}\right), x=(0.6-H / 300), y=(0.15-H / 200), v=0.3, w=0.15, z=0.1$ \\
\hline
\end{tabular}

$d=\mathrm{d}_{50}$ for model; $D=0.25$ for prototype for model

In general, researchers attempted to estimate the scour depth downstream of spillways using different methods such as experimental equations and physical models. Some common equations for predicting the scour depth $(D)$ or $(\mathrm{ds})$ are presented in Table 1 (Damle et al., 1966; Bhavan and Shahzafar Marg, 2010), where $H$ denotes the reservoir and tailwater head, $q$ is discharge per unit width, $d$ is grading size of the bed materials, $h_{t}$ the tailwater depth, and $\varphi$ is the flip bucket trajectory angle.

As mentioned above, although extensive studies have been conducted on scouring, there has been no comprehensive study on the effect of flip bucket slots with different shapes and configurations on scour downstream of this structure. In addition to the conduction of experiments on various models of scour downstream of flip buckets, the current study compared the obtained results with those of some experimental equations.

\section{MATERIAL AND METHODS}

\section{Dimensional analysis}

Effort was made in the current study to identify and extract dimensionless parameters based on parameters affecting scour, scour mechanism, and associated bed changes. Figure 1 depicts the formation of scour and parameters affecting this phenomenon. There are different parameters involved in the formation of scours below jet flows: discharge per unit width $(q)$, density of bed materials $\left(\rho_{s}\right)$, density of water $\left(\rho_{w}\right)$, dynamic viscosity $(\mu)$, acceleration due to gravity $(g)$, jet thickness at bucket $(b)$, nappe height or difference between reservoir head and tailwater head $(H)$, maximum scour depth, i.e. the distance from the primary bed level $(D)$, angle of jet impingement on tailwater $(\theta)$, radius of the flip bucket $(R)$, the flip bucket trajectory angle $(\varphi)$, vertical distance between the bucket lip and primary level $(Y)$, and time $(t)$. Therefore, the following conclusion can be made:

$$
f\left(q, \rho_{s}, \rho_{w}, D, d_{s}, h_{t}, g, b, Y, H, R, t, \theta, \mu, \cos \varphi\right)=0
$$

Since this study aimed to investigate the scour process in steady flow, time was neglected in this equation. In addition, since the investigated discharge rates were not expected to change significantly, this parameter was also excluded. On the other hand, since the calculation of $\theta$ is a very difficult task that makes the final equation complicated, it was also excluded (Vesalian et al., 2008). The highly turbulent flow in this study also allows us to eliminate the parameter $\mu$. As a result, the aforementioned function simplified to:

$$
f\left(q, \rho_{s}, \rho_{w}, D, d_{s}, h_{t}, g, Y, H, R, \cos \varphi\right)=0
$$

By selecting three iterative parameters $\left(q, \rho_{w}\right.$, and $\left.h\right)$, and using the Buckingham $\pi$ theorem, the following dimensionless equation was obtained:

$$
f\left(\frac{\rho_{s}}{\rho_{w}}, \frac{q}{\sqrt{g H^{3}}}, \frac{d_{s}}{H}, \frac{D}{H}, \frac{h_{t}}{H}, \frac{R}{H}, \frac{Y}{H}, \cos \varphi\right)=0
$$

In the present study, $R, Y, \rho_{s}, \rho_{w}, d_{s}$, and $\cos \varphi$ were excluded as constant parameters in the experiments. Finally, Eq. 4 was developed for the maximum scour depth prediction $\frac{D}{H}$ :

$$
f\left(\frac{q}{\sqrt{g H^{3}}}, \frac{h_{t}}{H}\right)
$$

On the other hand, the downstream head $\left(h_{t}\right)$ was considered constant, thereby the only dimensionless parameter $\left(\frac{q}{\sqrt{g H^{3}}}\right)$, i.e., Froude number, was obtained and regarded as the foundation of this study.

\section{Laboratory equipment}

To conduct the experiments and achieve the research objectives, a straight flume (0.6 in width, 0.6 in height and 12 in length) was installed in the Hydraulic Laboratory of the Department of Protection and Exploitation of Water Resources of Water and Electricity Organization of Khuzestan, Iran (Fig. 4). The flume was made of a metal sheet with glass walls. The flume was equipped with a digital flow meter at the input pipe and a manometer, along with a sharp-crested triangular spillway, at the end of the flume in the output basin for discharge regulation. A gate was used at the end of the flume to regulate and control downstream head.

The spillway modelled for these experiments was an ogee spillway with a flip bucket (radius $=0.16$ ) at its end (Fig. 5). The spillway (0.6 in width and 0.4 in height) was designed given the flume specifications, its maximum discharge, and USBR standard. The experiments were conducted with solid buckets, as well as slotted buckets with rectangular and triangular slots, each with two different configurations in terms of the distance between slots.

In these experiments, a specific type of material with a mean diameter of $5 \mathrm{~mm}$ was used. Regarding (i) the flow velocity $(u)$ and critical velocity $\left(u_{c}\right)$, obtained from the Shields equation, and (ii) occurrence of scour in clear water $1 \geq \frac{u}{u_{c}}$, this diameter was considered as the mean particle diameter.

$$
d_{m}=d_{50}=5 \mathrm{~mm}
$$

To achieve a steady state, a series of experiments with maximum discharge were conducted and it was determined that the maximum scour depth occurred after $120 \mathrm{~min}$, after which it remained unchanged and attained an equilibrium state.

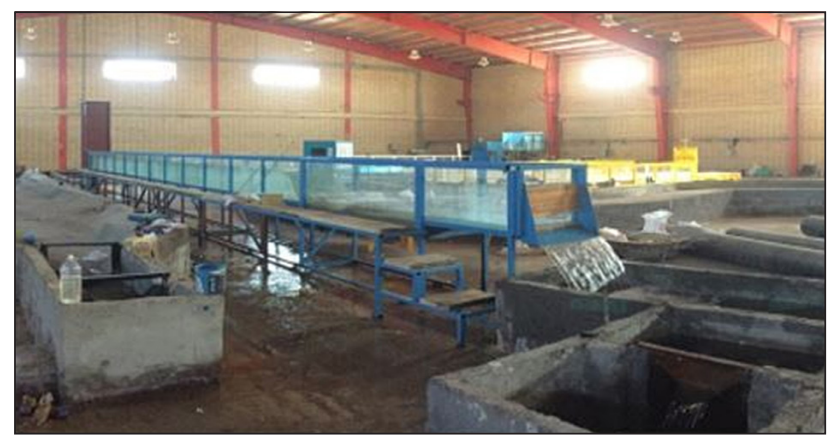

Figure 4. Laboratory flume 

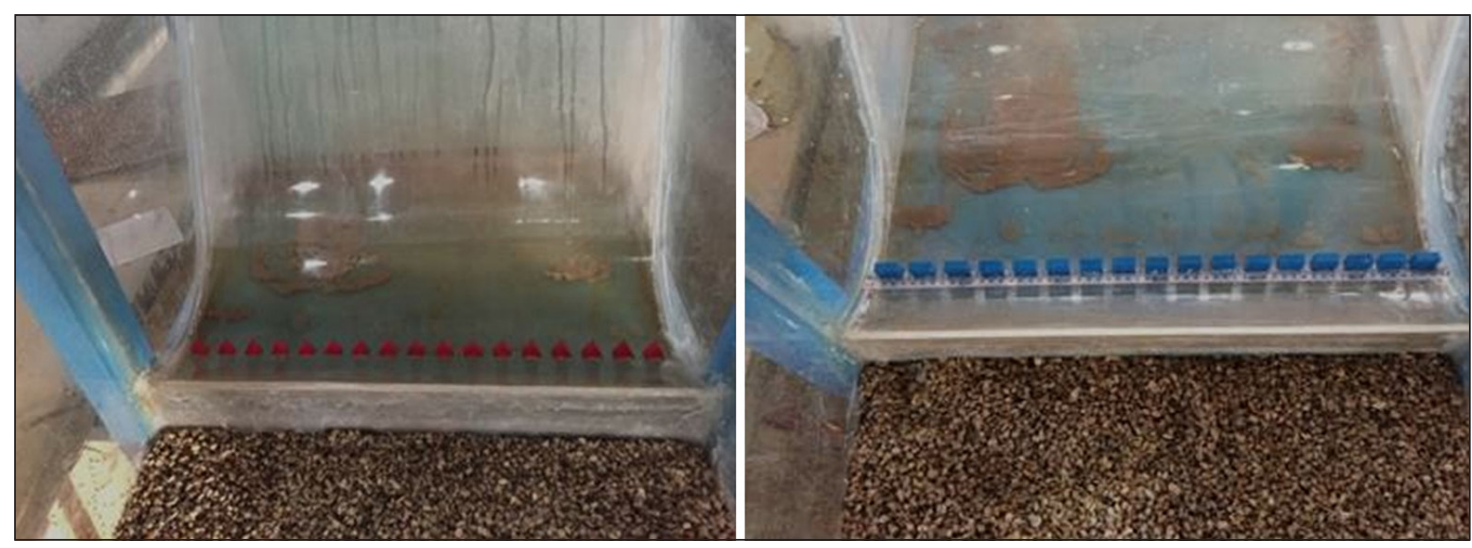

Figure 5. Flip bucket with rectangular and triangular slots in a continuous configuration according to USBR
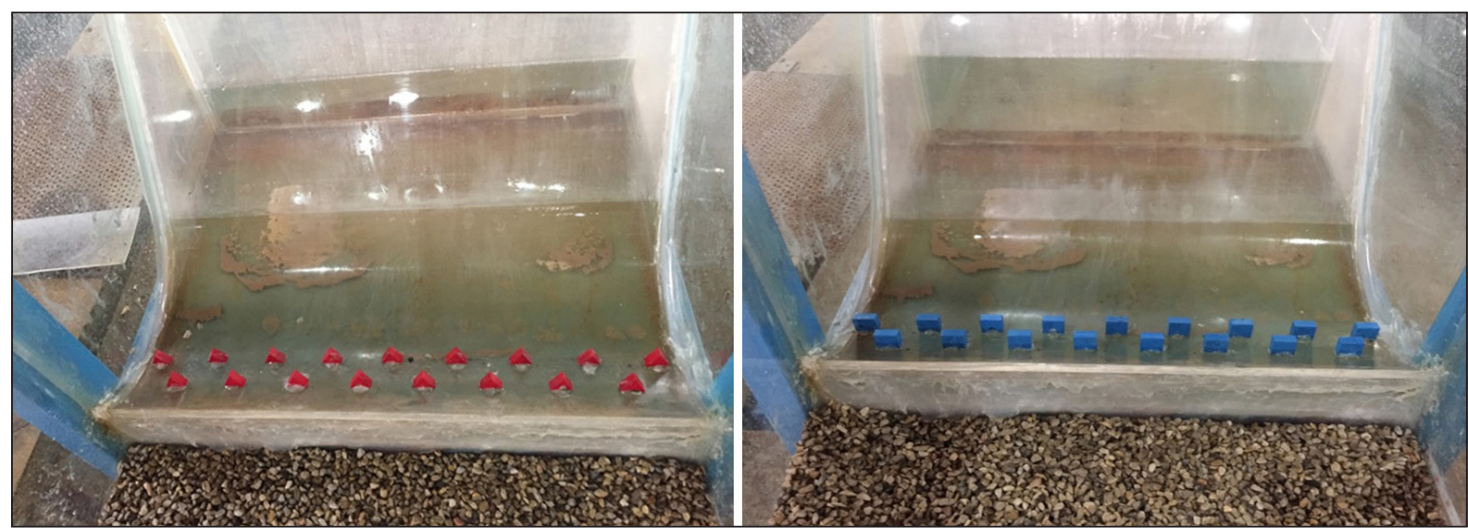

Figure 6. Flip bucket with rectangular and triangular slots in a labyrinth configuration (the current study)

\section{Experiments}

In this study, four different discharge rates in the range between 15 and $18 \mathrm{~L} / \mathrm{s}$ were used. The models used in this study included five solid flip buckets, and slotted rectangular and triangular flip buckets, each with two different slot configurations. A total of 20 experiments were conducted. The design and dimensions of the slots were considered based on USBR, so that the slot width was computed as $0.125 \times R$, the distance between the slots was computed as $0.05 \times R$, and the location of the slots from the bucket end was computed as $0.5 \times R$ (US Bureau of Reclamation, 1987). In the first case, the slots were configured based on USBR (Fig. 5). In the second case, the slots were configured with a labyrinth shape based on the method proposed by the researchers (Fig. 6).

Sediments were poured in a flume section with length of $2 \mathrm{~m}$, width of $0.6 \mathrm{~m}$, and depth of $0.15 \mathrm{~m}$, located immediately after the spillway. Then, the surface of the materials was flattened with a wooden leveller. To create a uniform density to ensure conditions and prevent unpredictable local changes, the surface of the material was hammered with a log and then was surveyed

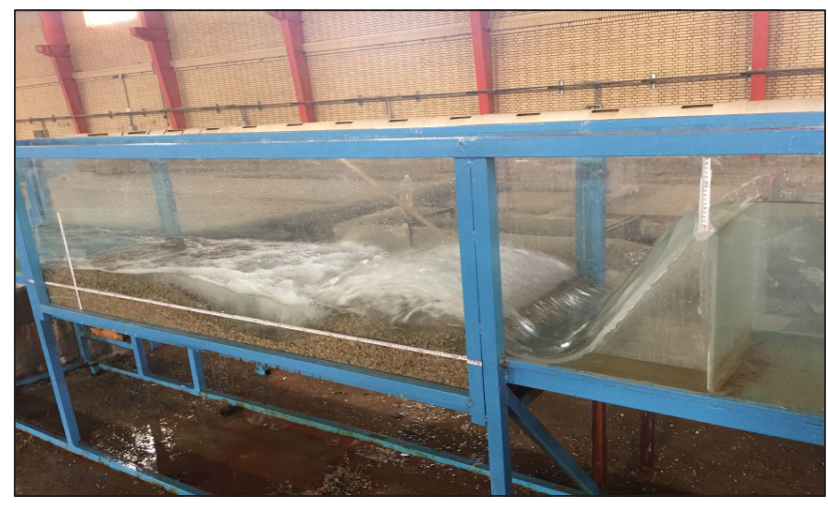

Figure 7. Impact of water jet with materials and formation of scour hole by a laser meter as the base level. The given discharge was then regulated with an electromagnetic flow meter. On the other hand, the downstream head was regulated using a gate at the end of the flume. In these experiments, the tailwater depth was considered constant and equal to the end heel of the bucket, i.e., $80 \mathrm{~mm}$. The input flow into the flume impinged on the sediment basin and formed a scour hole after passing over the spillway and leaving the flip bucket (Fig. 7). At the end of the experiment, the input flow was closed and the materials were drained. Then, the bed level changes were captured using topographic imaging.

\section{RESULTS AND DISCUSSION}

\section{Changes in scour depth}

The scour depth increases by increasing the flow input to the spillway. This study showed that this depth varies in different models with different slot shapes and configurations. First, the effect of the shape and configuration of the slots in each model was investigated. Table 2 presents the results from the scour depth experiments (in $\mathrm{mm}$ ) in the different models with a discharge ranging from $15-18 \mathrm{~L} / \mathrm{s}$. The Froude numbers corresponding to $15 \mathrm{~L} / \mathrm{s}, 16 \mathrm{~L} / \mathrm{s}, 17 \mathrm{~L} / \mathrm{s}$, and $18 \mathrm{~L} / \mathrm{s}$ were $0.353,0.376,0.4$, and 0.423 , respectively.

Table 2. Scour depth in $\mathrm{mm}$

\begin{tabular}{lcccc}
\hline Model type & \multicolumn{4}{c}{ Discharge (L/s) } \\
\cline { 2 - 5 } & 15 & 16 & 17 & 18 \\
\hline Control & 96 & 98 & 103 & 105 \\
Continuous rectangular & 33 & 57 & 88 & 138 \\
Labyrinth rectangular & 21 & 26 & 47 & 49 \\
Continuous triangular & 73 & 79 & 106 & 120 \\
Labyrinth triangular & 56 & 76 & 92 & 100 \\
\hline
\end{tabular}




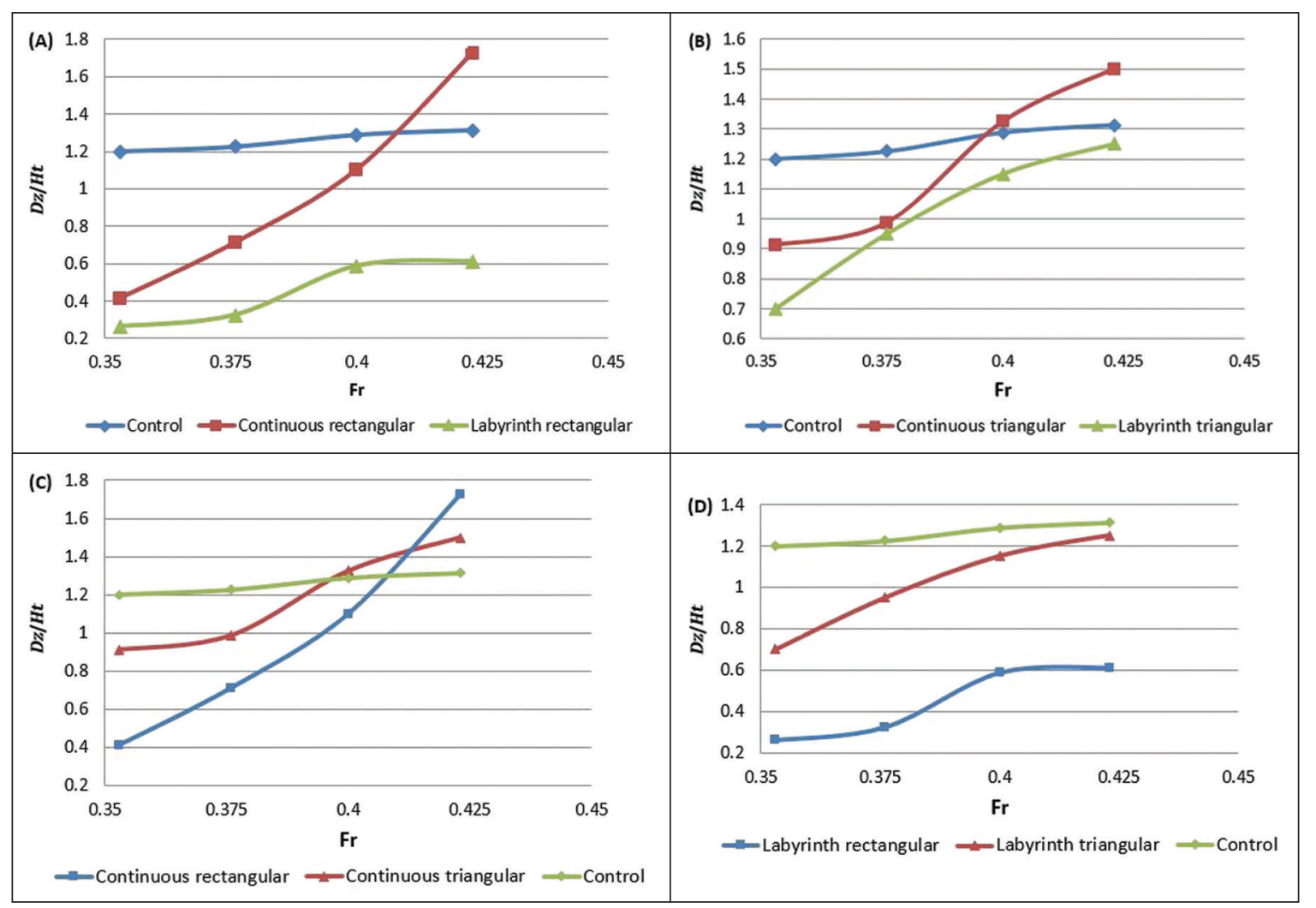

Figure 8. Changes in scour depth under different conditions: (A) maximum scour depth under control, continuous rectangular slot and labyrinth rectangular slot; (B) maximum scour depth under control, continuous triangular slot and labyrinth triangular slot: (C) maximum scour depth under control, continuous rectangular slot and continuous triangular slot; (D) maximum scour depth under control, Labyrinth rectangular slot, labyrinth triangular slot

For the effect of discharge, slot shape, and slot configuration on the scour hole, the following results were obtained: As shown in Fig. 8a-c, a greater reduction in scour depth is observed by increasing the discharge rate in the USBR-based rectangular and triangular slotted bucket with continuous configuration than in the control group. However, this reduction in depth continues until the Froude number reaches 0.4 ; afterwards, the scour depth exceeds that for the control group. On the other hand, the scour depth for all the studied parameter values was lower in the rectangular and triangular cases with labyrinth configuration (the present study) than in the control and rectangular and triangular cases with continuous configuration. The presence of continuous slots leads to a blockage in the bucket, causing formation of a vortex that inhibits desirable flow of water from the slots. After passing through the spillway chute and reaching the bucket slots, the flow strikes the bucket slots and the vortex formed around them, leading to an upward jet with a height higher than that of the control group by increasing the flow rate. As a result, the jet length reduces as compared to the control, but collides with the downstream head from a great height. Therefore, the scour depth increases in the rectangular and triangular slotted buckets with continuous configuration. In the case of rectangular and triangular slotted buckets, the dissipation system works in the following way: a portion of flow strikes the first row of the slots and its energy is dissipated, and the rest discharges into the downstream area in the form of a jet. Meanwhile, a portion of the stream passes the first row and hits the second row shortly afterward. It should be noted that two different jets are created with this type of structure, one with a large height and short length which is caused by the first row of slots, and the other with a low height and a greater length as a result of flow passing through the slots. Collision of these two jets in the downstream area results in a great dissipation of energy and reduces scour depth.

After it was established that the labyrinth configuration was more efficient than the continuous configuration, the shape of the slots under the labyrinth scenario was examined. According to Fig. 8d, the maximum scour depth under the scenario with rectangular slots in labyrinth configuration was less than that under the triangular slots scenario with the same configuration. This can be attributed to the slot shape as the contact surface of the flow with the rectangular slots was greater than that with the triangular slots. As a result, a portion of energy was dissipated in the former configuration and the jet flow struck the downstream surface with a lower energy after reforming into a jet.

As shown in Table 2 and Fig. $8 \mathrm{~d}$, the optimal scenario was achieved in the case of rectangular slots with labyrinth configuration, giving a $53 \%$ reduction in the maximum scour depth as compared to the control.

Figures 9 and 10 show the scour which is formed under maximum discharge, labyrinth rectangular and triangular slots.

\section{Comparison of results with empirical equations}

As shown in Table 3, many experimental equations have been developed for estimation of the maximum scour depth. Regarding the similarity of results in the current study, results from Damle-A, Damle-B, and Taraimovich equations were compared and tabulated.

Table 3. Maximum scour depth $(\mathrm{mm})$ obtained from experimental equations

\begin{tabular}{lcccc}
\hline Experimental equation & \multicolumn{4}{c}{ Discharge (L/s) } \\
\cline { 2 - 5 } & $\mathbf{1 5}$ & $\mathbf{1 6}$ & $\mathbf{1 7}$ & $\mathbf{1 8}$ \\
\hline Damle-A & 64.6 & 66.7 & 67.8 & 70.7 \\
Damle-B & 56.1 & 57.9 & 59.7 & 61.5 \\
Taraimovich & 45.3 & 47.3 & 49.2 & 51.1 \\
\hline
\end{tabular}



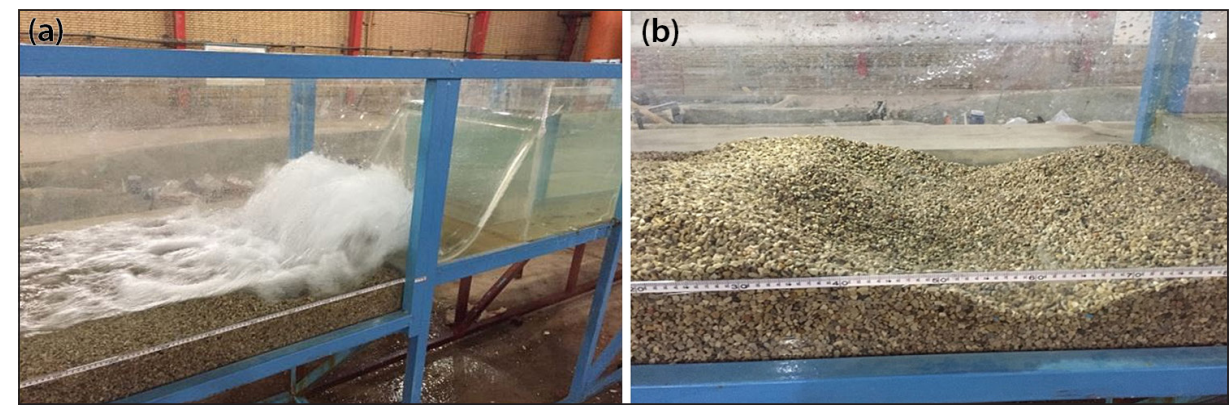

Figure 9. Scour formed under maximum discharge, and labyrinth rectangular slots: (a) jet under labyrinth rectangular scenario; (b) scour under labyrinth rectangular scenario
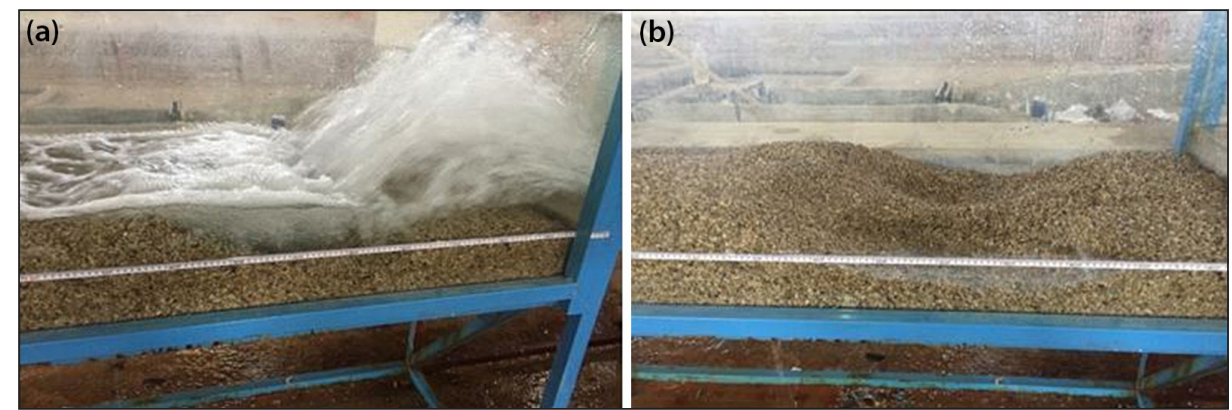

Figure 10. Scour formed under maximum discharge, and labyrinth triangular slots (a) jet under labyrinth triangular scenario; (b) scour under labyrinth triangular scenario

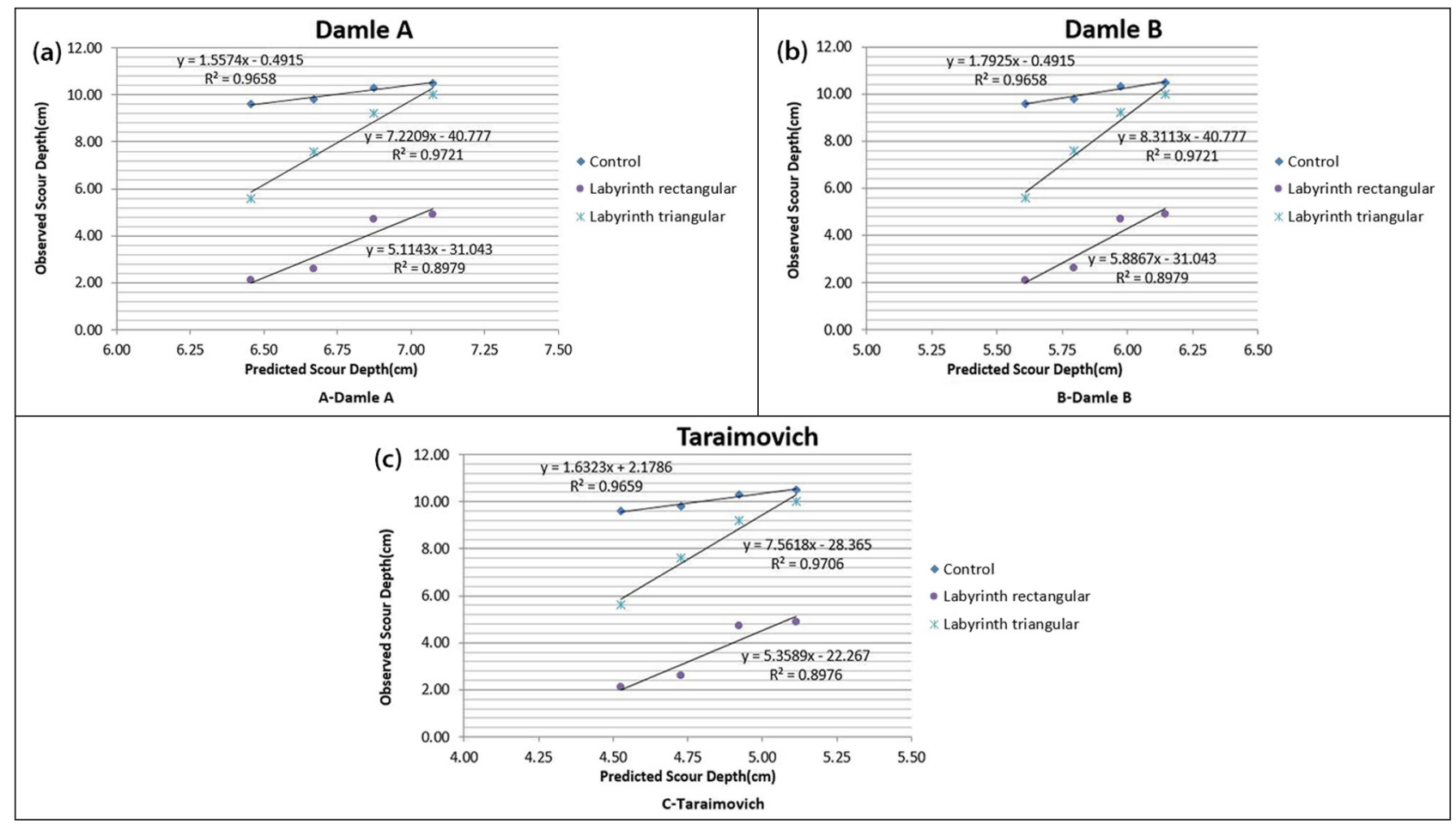

Figure 11. Comparison of experimental equations with results under control, continuous rectangular slots, and dentate rectangular slot scenarios: (a) Damle-A, (b) Damle-B, (c) Taraimovich

According to the results, the Taraimovich equation $\left(R^{2}=0.9659\right)$ was the most consistent with observational results under the control scenario, whereas in the optimal scenario (i.e. the labyrinth configuration), the Damle equations corresponding to $R^{2}=0.879$ and $R^{2}=0.9721$ had the best performance in rectangular and triangular configurations, respectively (Fig. 11a-c).

\section{CONCLUSION}

The main objective of this study was to investigate the effect of slots on topographical changes in a bed with uniform noncohesive materials below a jet discharging from a spillway with flip buckets. Hence, the experiments were conducted based on discharge and slot shape and configuration under five scenarios: namely, in the absence of slots (i.e. the solid or control case) and in the presence of rectangular and triangular slots for two configurations (continuous and labyrinth). Results showed that the scour depth increases by increasing the discharge in all five scenarios. However, the increase in scour depth was slower in the slotted buckets with rectangular slots in the labyrinth configuration than other bucket types, such that the maximum scour depth at peak discharge was reduced by $53 \%$ as compared to the control. Comparison of the results with those of three experimental equations developed by other researchers revealed that they all produced roughly realistic results. In general, the 
Taraimovich equation produced more realistic results under the control scenario, while Damle-A and Damle-B yielded more realistic results under rectangular and triangular slotted scenario with labyrinth configuration.

\section{ACKNOWLEDGMENTS}

The authors would like to thank the Water and Power Authority of Khuzestan, Iran for their support in providing the required laboratory equipment.

\section{REFERENCES}

AKBARI GH, KAVIANPOUR M and SOLTANI-SAMAN A (2013) In vitro study on scour downstream of flip bucket. J. Water Resour. Eng. 7 (20) 51-64. https://www.sid.ir/Fa/Journal (Accessed 5 May 2013). (In Persian.)

AMANIAN N (1993) Scour below a flip bucket spillway. PhD thesis, Utah State University. Department of Civil and Environmental Engineering.

AZMATHULLAH HMD, DEO MC and DEOLALIKAR PB (2005) Neural networks for estimation of scour downstream of flip bucket. J. Hydraul. Eng. 131 (10) 898-908. https://doi.org/10.1061/ (ASCE)0733-9429(2005)131:10(898)

BHAVAN M and SHAHZAFAR MARG B (2010) Bureau of Indian Standards. Central for Hydraulic Design of Bucket Type Energy Dissipators. Second Revision. Bureau of Indian Standards, New Delhi.

CHEE SP and PADIYAR PV (1969) Erosion at the base of flip buckets. Eng. J. Can. 52 (11) 22-24.

DAMLE PM, VENKATRANMAN CP and DESAI SC (1966) Evaluation of scour below flip buckets of spill-ways. In: CWPRS Golden Jubilee Symposia, Poona, India.

HAGER WH and MINOR HE (2004) Plunge pool scour in prototype and laboratory. In: Proceedings of the International Conference, hydraulics of dam and river structures, 26-28 April 2004, Tehran, Iran.

HOFFMANS GJCM and VERHEIJ HJ (1997) Scour Manual: A.A. Balkema, Rotterdam.

MAHBOOBI A (1996) Effect of material diameters on scour of freenappe jets. MSc thesis, University of Science and Technology of Iran, Department of Civil Engineering, Iran. https://ganj.irandoc.ac.ir (Accessed 5 July 1996). (In Persian.)

MARTIN RBF (1975) Scouring of rocky river beds by free jet spillway. Int. Water Power Dams Construct. 27 (4) 152-153.
MASON PJ (1984) Erosion of plunge pools downstream of dams due to the action of free trajectory jets. Proc. Inst. Civ. Eng. 76 (5) 523-537. https://doi.org/10.1680/iicep.1984.1257

MASON PJ and ARUMUGAM K (1985) Free jet scour below dams and flip buckets. J. Hydraul. Eng. 111 (2) 220-235. https://doi.org/10.1061/ (ASCE)0733-9429(1985)111:2(220)

MAZUREK KA and RAJARATNAM N (2003) Erosion of sand by circular impinging water jets with small tailwater. J. Hydraul. Eng. 139 (3) 225-229. https://doi.org/10.1061/(ASCE)0733-9429(2003)12 9:3(225)

MEHR-KIA M, MAJDZADEH M and KAVIANPOUR M (2012) Evaluation of equations governing turbulence at flip downstream using field and laboratory data. In: Proceedings of $11^{\text {th }}$ Iranian Hydraulic Conference on Hydraulics, 16-18 November 2012, University of Urmia and the Iranian Hydraulic Association under the auspices of Civillas, Urmia, Iran. https://www.civilica.com/Paper-IHC11-IHC 11_206 (Accessed 30 Nov 2012). (In Persian.)

MOMENI-VESALIAN R, MOUSAVI-JAHROUMI V and SHAFAE BAJESTAN M (2009) Scour downstream of rectangular jet flows with non-uniform materials. J. Agric. Sci. Nat. Resour. 15 (2) 1-15. [In Persian].

PIRESTANI MR and RIAZI R (2015) Laboratory study of the effect of the slot and the degree of opening of the valve in the flip bucket on the shape of the substrate profile with non-uniform materials. Iranian Water Res. J. 18 (3) 131-140. (In Persian.)

PIRESTANI MR, MANSOURI A and SHAFIEI HASANABADI S (2009) Laboratory investigation of the effect of the depth of tail water on the dimensions of the scour hole due to the flip slotted falling jet. In: Proceedings of the $8^{\text {th }}$ Iranian Hydraulic Conference, 24-26 Dec 2009, University of Tehran. https://www.civilica.com/ PdfExport-IHC08_125 (Accessed 5 Jan 2010). (In Persian).

SCHOKLITSCH A (1935) Prevention of Scour and Energy Dissipation. Translated at the USBR, USA.

TARAIMOVICH II (1978) Deformation of channels below high head spillways on rock foundations. Hydrotech. Construction (USSR). 8 (9) 917-923. https://doi.org/10.1007/BF02322089

US BUREAU OF RECLAMATION (1987) Design of Small Dams. A Water Resources Technical Publication. ( $3^{\text {rd }}$ edn). United States Department of the Interior (USBR).

VERONESE A (1937) Erosioni de fondo a valle diuno scarico. Ann. Lavori Publicci. 75 (9) 717-726.

VISCHER DL and HAGER WH (1995) Energy dissipators. In: Hydraulic Structures Design Manual. No. 9. A. A. Balkema, Rotterdam. 